\title{
Emodin Induces Death in Human Cervical Cancer Cells Through Mitotic Catastrophe
}

\author{
WOJCIECH TRYBUS ${ }^{1}$, TEODORA KRÓL ${ }^{1}$, EWA TRYBUS ${ }^{1}$, ANNA STACHURSKA ${ }^{2}$, \\ GRZEGORZ KRÓL ${ }^{3}$ and ANNA KOPACZ-BEDNARSKA ${ }^{1}$ \\ ${ }^{1}$ Department of Cell Biology and Electron Microscopy, Institute of Biology, \\ The Jan Kochanowski University, Kielce, Poland; \\ ${ }^{2}$ Department of Immunohematology, Centre of Postgraduate Medical Education, Warsaw, Poland; \\ ${ }^{3}$ Faculty of Management, University of Warsaw, Warsaw, Poland
}

\begin{abstract}
Background: Anthraquinones, including emodin, are compounds with numerous pharmacological properties, including anticancer properties. The aim of this study experiment was to examine the effect of emodin, a natural compound present in the roots and rhizomes of Rheum palmatum, on the induction of mitotic catastrophe in cervical cancer cells. Material and Methods: HeLa cells were treated with different emodin concentrations for $48 \mathrm{~h}$, and cell growth was measured with 3(4-,5-dimethylthiazol-2-yl)-2,5-diphenyltetrazolyl. The cell-cycle distribution and the level of apoptosis were determined by means of flow cytometry, using annexin V-fluorescein isothiocyanate staining and propidium iodide. Morphological changes in the mitotic apparatus were evaluated using optical and confocal microscopy techniques. Results: Emodin induced an increase in the number of polymorphonuclear cells, giant cells, cells with micronuclei, cells with abnormal mitosis and damaged spindle. The reorganization of F-actin depended on the concentration of emodin. With the increase in emodin concentration, inhibition of mitotic activity was demonstrated, which was manifested by a decrease in the mitotic index, mainly in metaphase of the mitotic process and an increase in the number of cells inhibited in the $G_{2} / M$ phase. At the same time, an increase in the number of apoptotic cells was found. Conclusion: Emodin leads to death of cervical cancer cells by induction of a mitotic catastrophe.
\end{abstract}

Cancer is one of the greatest problems of modern medicine. Conventional treatment methods still do not produce satisfactory results for some cancer types, and the resulting side-effects are often extensive. This has led to the search for

Correspondence to: Wojciech Trybus, Department of Cell Biology and Electron Microscopy, Institute of Biology, The Jan Kochanowski University, Świętokrzyska 15, 25-406 Kielce, Poland. E-mail: wojciech.trybus@ujk.edu.pl

Key Words: Emodin, mitotic death, F-actin, cell cycle, apoptosis. other solutions, e.g. the possibility of using natural medicine in oncological therapy, including compounds of plant origin. One example is emodin $\left(\mathrm{C}_{15} \mathrm{H}_{10} \mathrm{O}_{5}\right)$, isolated from the roots and rhizomes of Rheum officinale Baill. and Rheum palmatum L. Emodin is an anthraquinone with multifaceted antitumor activity, including proapoptotic $(1,2)$ and anti-proliferative effects $(3,4)$. It also influences changes in the lysosomal system of cancer cells (5).

The aim of the presented study was to demonstrate the effect of emodin on the induction of a mitotic catastrophe, an alternative type of cell death, in cervical cancer cells.

\section{Materials and Methods}

In vitro culture conditions. Cervical cancer cells (HeLa) were grown on Dulbecco's modified Eagle's medium supplemented with $10 \%$ fetal bovine serum with $1 \%$ antibiotic mixture (Thermo Fisher Scientific, Waltham, MA, USA) in a $\mathrm{CO}_{2}$ DirectHeat incubator (Thermo Fisher Scientific). Emodin was purchased from SigmaAldrich (St. Louis, MO, USA). Cells were exposed to emodin concentrations of 1, 15, 30, 60 and $100 \mu \mathrm{M}$ for 24 and $48 \mathrm{~h}$.

Assessment of morphological changes and determination of the mitotic index. Cells (control and test) were grown on sterile coverslips in plastic dishes (Nunc; Thermo Fisher Scientific). After exposure to emodin, the cells were fixed in methanol and stained with Harris hematoxylin and eosin (Sigma-Aldrich). The cells were then dehydrated using an increasing alcohol series and overexposed in xylene. Morphological analysis was performed using a Nikon Eclipse 80i microscope with Nikon NIS Elements D 3.10 software (Nikon Instruments, Amsterdam, the Netherlands). In the preparations, 5,000 cells were analyzed in three independent experiments $(15,000$ cells per concentration per incubation time). The existence of mitotic catastrophe was determined on the basis of morphological markers, i.e. the presence of giant cells, polymorphonuclear cells, micronucleated cells and cells inhibited in metaphase of the mitotic process.

Analysis of the cell cycle. Cells incubated for 48 hours with emodin at a concentration of $1 \mu \mathrm{M}$ and $100 \mu \mathrm{M}$ were fixed in $70 \%$ ethanol and then labeled with a mixture containing $0.1 \% \mathrm{NP}-40,10 \mu \mathrm{g} / \mathrm{ml}$ 
of DNAase-free RNAse and $5 \mu \mathrm{g}$ of propidium iodide. After 15 minutes of incubation, the cells were analyzed using a FACSCanto II cytometer and the FACSDiva program (BD Biosciences, San Jose, CA, USA). The percentage of cells in individual phases of the cycle was determined using ModFit LT 4.1.7 software (Verity Software House, Topsham, ME, USA).

Proliferation and viability test. After 48-hour incubation with emodin at concentrations of $1-100 \mu \mathrm{M}$, the cells were incubated with a solution of 3-(4,5-dimethylthiazol-2-yl)-2-5-diphenyltetrazolium bromide (MTT) (Sigma-Aldrich) on 96-well plates (Nunc) according to the modified Mossmann method (6). The formed formazan crystals were dissolved in dimethyl sulfoxide and the absorbance was measured using a multi-sensing microplate reader Synergy 2 (BioTek, Winooski, VT, USA).

Detection of apoptosis: Double staining of annexin V/propidium iodide $(P I)$. The cells were treated with emodin at concentrations of $1 \mu \mathrm{M}$ and $100 \mu \mathrm{M}$ for 48 hours, and then stained using the annexin V-fluorescein isothiocyanate (FITC) test and PI (BD Pharmingen, San Jose, CA, USA). Apoptotic cells were analyzed using a FACSCanto II flow cytometer using FACSDiva software (BD Biosciences).

Fluorescent staining of F-actin. Fluorochromes were purchased from Sigma-Aldrich. Cells were grown on sterile microscope slides in dishes. After $24 \mathrm{~h}$ of incubation, the cells were treated with emodin for $48 \mathrm{~h}$ and then fixed in $3.7 \%$ paraformaldehyde. The cells were washed in phosphate-buffered saline and then permeabilized in 0.2 Triton X-100 (Sigma-Aldrich). The cells were then stained in the dark with FITC conjugated phalloidin. In addition, cell nuclei were stained with 4',6-diamidyno-2-fenyloindol. Finally, the cells were rinsed and closed in Fluoromount medium (Sigma-Aldrich). The actin filaments were examined using a Nikon A1R confocal microscope (Nikon Instruments).

Statistical analysis. The significance of the differences obtained was determined using statistical analysis carried out using Statistica 10.0 software (StatSoft Krakow, Poland). The morphological results were evaluated using the non-parametric chi-square test, cell viability assay and apoptosis by Tukey test, and the cell-cycle distribution by Newman-Keuls test. Differences were confirmed statistically at $p<0.05$.

\section{Results}

Emodin reduced the mitotic index. Incubation of HeLa cells with increasing emodin concentrations for 24 and 48 hours caused a statistically significant reduction in the mitotic index. Emodin at $100 \mu \mathrm{M}$ led to the highest inhibition of cell division to $7.4 \%(24 \mathrm{~h}$ ) and $4.2 \%$ (48 h) (Figure 1A). At the same time, it was shown that cells blocked in the metaphase stage constituted $87.5 \%$ of the cells ( $24 \mathrm{~h}$ incubation) and $89 \%$ (48 h incubation) of dividing cells (Figure 1B).

Emodin disturbed the cell cycle. Cells treated with emodin exhibited significant changes in the cell cycle. Cytometric analysis performed by PI staining showed that emodin induced cell arrest in the $\mathrm{G}_{2} / \mathrm{M}$ phase, which was evidenced by a significant increase in the percentage of cells $(63.95 \%)$ in the $\mathrm{G}_{2} / \mathrm{M}$ phase (100 $\mu \mathrm{M}$ emodin) compared to $8.27 \%$ cells in the $\mathrm{G}_{2} / \mathrm{M}$ phase after $1 \mu \mathrm{M}$ concentration of emodin and to the control $(7.14 \%)$. This correlated with the simultaneous decrease in cells in the $\mathrm{G}_{0} / \mathrm{G}_{1}$ phase to $26.91 \%$ at the concentration of $100 \mu \mathrm{M}$ emodin. The control cells in this phase accounted for $75.54 \%$ (Figure 2).

Emodin induced mitotic death. As a result of exposure of cells to different concentrations of emodin, after both 24 and 48 hours, the number of cells undergoing mitotic catastrophe increased. An increased number of polymorphonuclear cells was observed with nuclear envelope and active nuclei markedly around the nucleus. The highest increase was observed at $30 \mu \mathrm{M}$, at both 24 and $48 \mathrm{~h}$, compared to the control (Figure 3). The number of cells with micronuclei present in the cytoplasm of cells also increased as a result of abnormal chromosome segregation and giant cells. Giant cells were characterized by a significant increase in size, presence in the cytoplasm of both micronuclei and large asymmetric nuclei, and numerous nuclei differentiated in both quantity and shape. Cells with abnormal chromosome segregation were also observed in all phases of division, including abnormal metaphases (bipolar, three-pole and multipolar) (Figure 4). The greatest increase in mitotic changes was observed after $48 \mathrm{~h}$ of incubation of cells with emodin.

Emodin reduced the viability and induced cell apoptosis. Incubation of cells for $48 \mathrm{~h}$ with emodin in the concentration range 1-100 $\mu \mathrm{M}$ resulted in a gradual decrease in cell viability. The highest inhibition of cell proliferation (determined by the MTT test) was demonstrated at a concentration of $100 \mu \mathrm{M}$. The concentration inhibiting cell growth by $50 \%$ was $56.91 \mu \mathrm{M}$, whereas the concentration inhibiting $90 \%$ cell growth was $73.3 \mu \mathrm{M}$ (Figure 5A). The decrease in viability correlated with simultaneous increase in the percentage of apoptotic cells (annexin test). Even at a concentration of $1 \mu \mathrm{M}$, the apoptotic cells, both early and late apoptotic, were found. A statistically significant increase in the percentage of cells with a late apoptotic phenotype (96.87\%) (Figure 5B) was found as a result of 48-hour exposure to $100 \mu \mathrm{M}$.

Emodin induced damage to the cytoskeleton. As a result of emodin, changes in the cytoskeleton organization of the examined cells were observed. Control cells were characterized by a regular system of F-actin in the cytoplasm. Emodin at $30 \mu \mathrm{M}$ caused an increase in the fluorescence intensity of the labeled fibers. Cells treated with $45 \mu \mathrm{M}$ emodin were characterized by reorganization of the cytoskeleton, change of shape and small deposits of actin present in the cytoplasm. In contrast, the emodin at $100 \mu \mathrm{M}$ induced changes in the cytoskeleton indicating damage, 

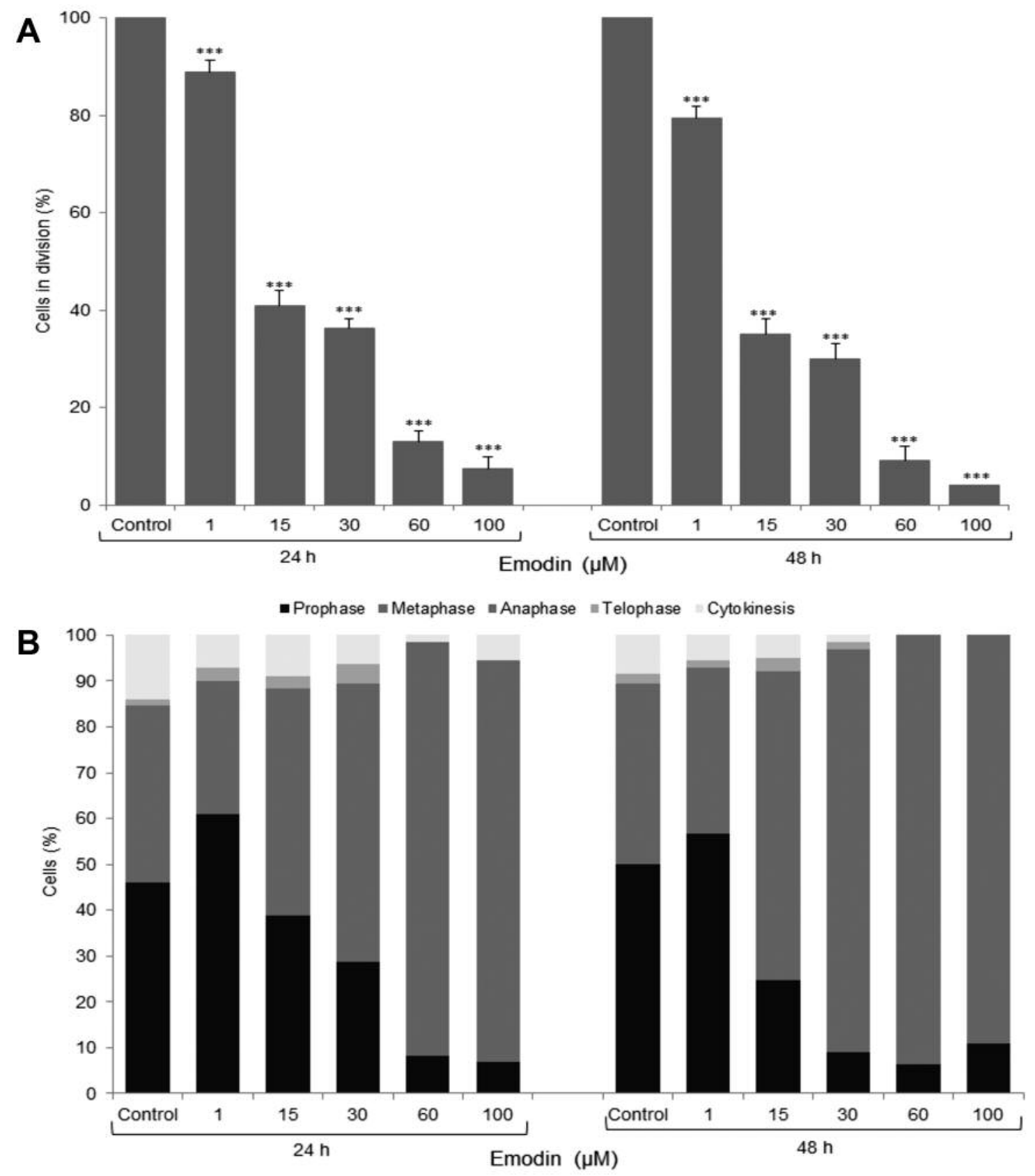

Figure 1. A: Mitotic index of HeLa cells after 24-and 48-hour incubation with different concentrations of emodin. The results are the average of three replications for each treatment group. ${ }^{* * *}$ Differences confirmed statistically at $p<0.001$. B: The percentage of HeLa cells in individual phases of mitosis after 24-and 48-hour exposure to different concentrations of emodin.

reflected by a reduced number of actin fibers or their absence, as well as the presence in the cytoplasm of cells of large actin aggregates, often distributed around the nucleus. The cells were also significantly elongated. Giant cells with disrupted distribution of actin microfilaments were also observed. In addition, rounded cells with condensed actin were present (Figure 6).

\section{Discussion}

Mitotic catastrophe is a type of cell death that occurs as a result of cell-cycle disorders, abnormal chromosome segregation and cell division, which results in the presence of nuclear changes that lead to the formation of cells with micronuclei, polymorphonuclear cells and giant cells (7-9). 


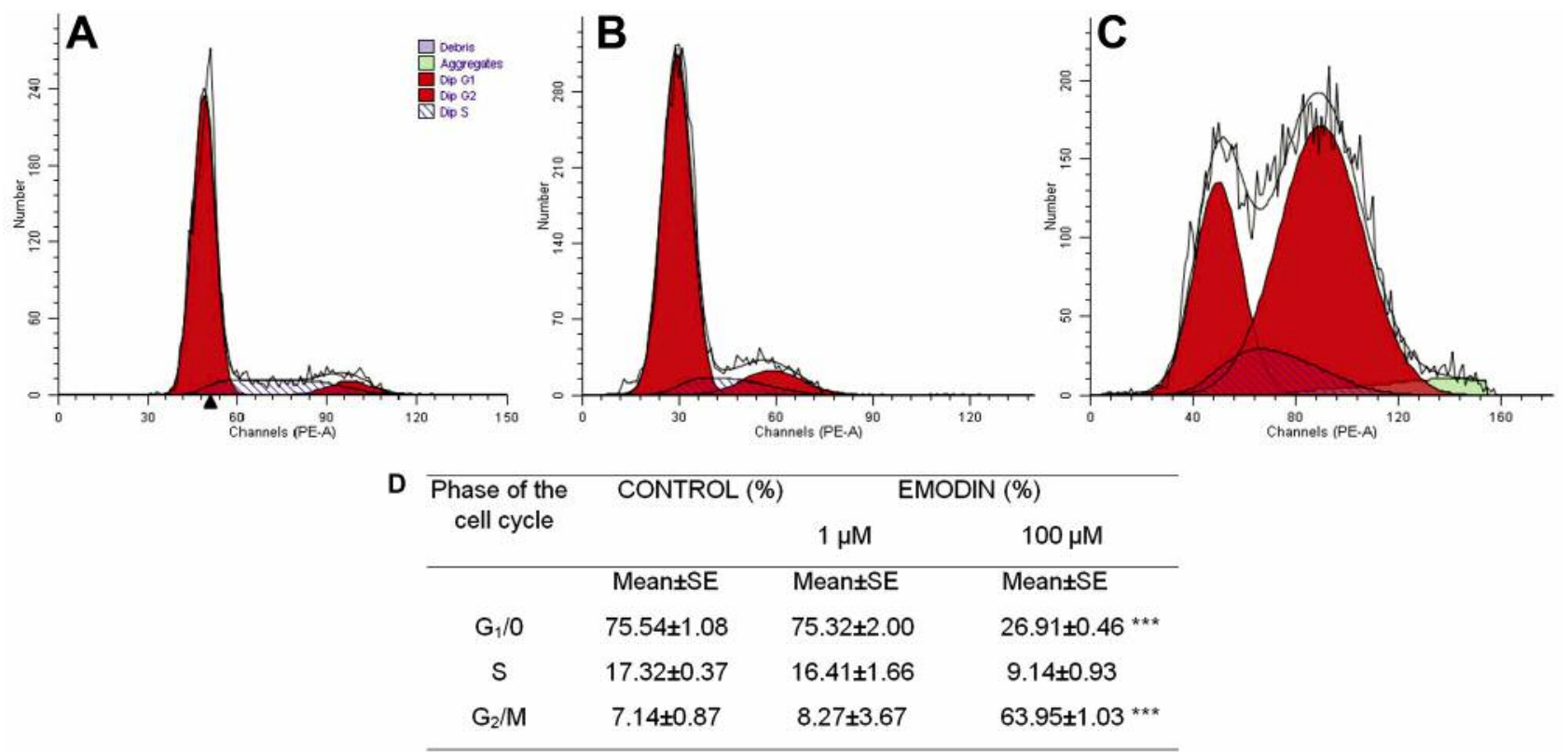

Figure 2. Distribution of HeLa cells in the cell cycle as a result of 48-hour action of emodin. A: Control cells. Cells treated for 48 hours with emodin at B: $1 \mu \mathrm{M}$ and C: $100 \mu \mathrm{M}$. D: Percentage of HeLa cells in different phases of the cell cycle as a result of treatment with different concentrations of emodin. The data correspond to the mean \pm standard error (S.E.) from three different experiments. ${ }^{* *}$ Differences confirmed statistically at $p<0.001$.

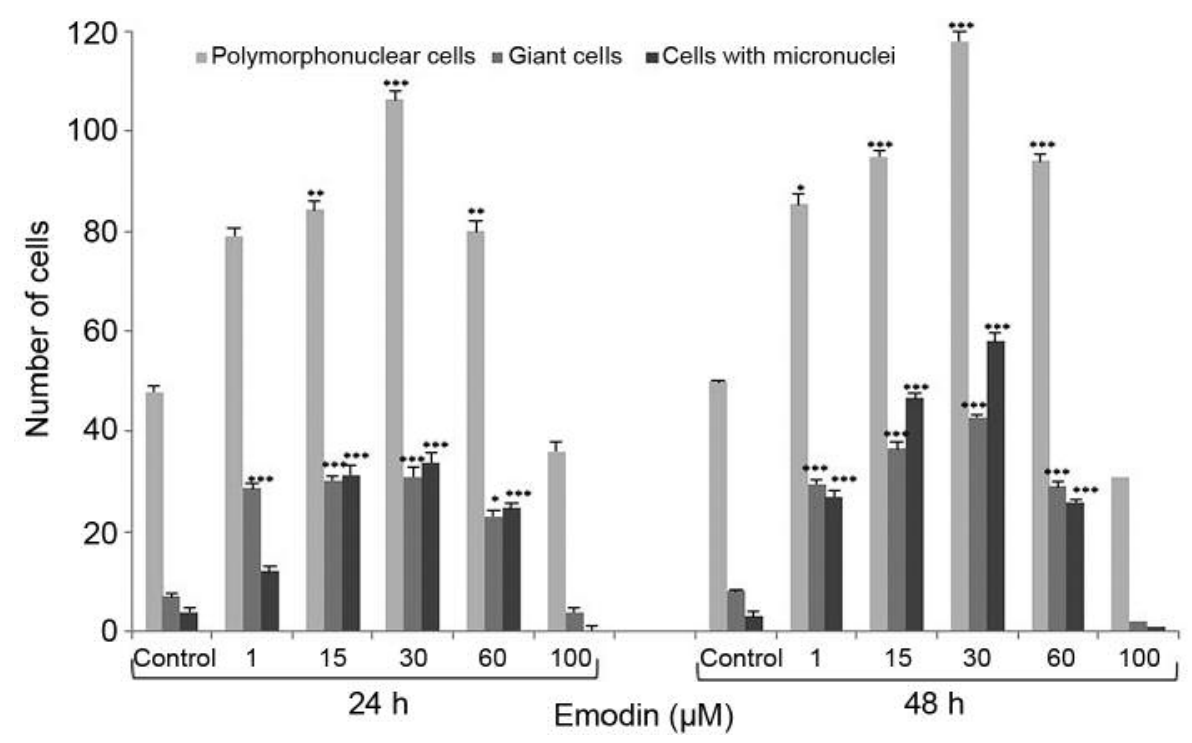

Figure 3. Comparison of the number of polymorphonuclear cells, giant cells and cells with micronuclei after 24- and 48-hour exposure of HeLa cells to different concentrations of emodin. Differences confirmed statistically at: $* p<0.05 ; *^{*} p<0.01 ; * * * p<0.001$.

From the biochemical point of view, mitotic catastrophe is accompanied by increased permeability of the mitochondrial membrane and the activation of caspases, which resembles the process of apoptosis. However, it is still unclear whether mitotic catastrophe causes cell death with or without caspase action $(10,11)$. As an alternative type of cell death, mitotic catastrophe is a desirable process in anticancer therapy, being particularly important in cancer cells that have blocked pathways leading to apoptosis.

Among compounds that have antitumor potential are anthraquinones, including emodin under investigation here. According to our findings, this compound induced mitotic 


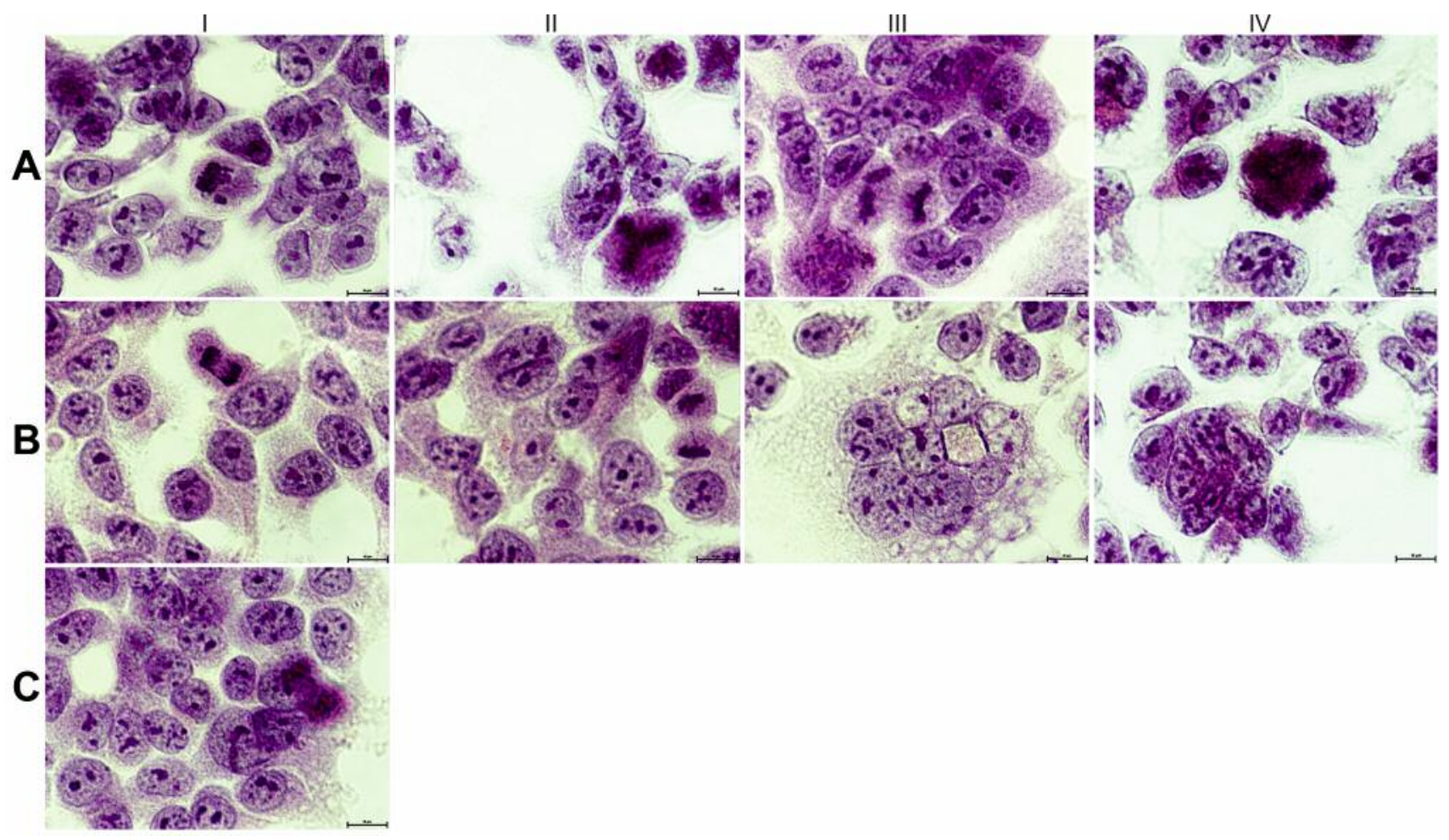

Figure 4. Morphological changes in HeLa cells treated with $30 \mu \mathrm{M}$ emodin for 48 h demonstrating mitotic catastrophe. A: Cells with abnormal chromosomal segregation and chromosomes remaining in the cytoplasm, not pulled down to the poles during different phases of cell division: I: Cells with abnormal metaphase, II: bipolar, III: three-pole, IV: multipolar. B: Various abnormalities: I: Incorrect anaphase, II: incorrect telophase, III: giant cell, IV: cell with micronuclei. C: Control cells at interphase and with normal cell division. Hematoxylin and eosin staining. Magnification $\times 1000$.

death in cervical cancer cells. Cytotoxicity of emodin was, among others, due to antimitotic activity, since a concentration as low as $1 \mu \mathrm{M}$ inhibited cell division. At $100 \mu \mathrm{M}$, a significant suppression of cell division was demonstrated (mitotic index $=4.10$ ), where $89 \%$ ( $48 \mathrm{~h}$ ) were cells in the metaphase of mitotic division (Figure 1), which is associated with an incorrect configuration of the mitotic spindle. The influence of emodin on cytoskeletal changes was also manifested by the presence of cells with abnormal chromosomal segregation and abnormal mitotic figures (Figure 4). Other emodin-induced morphological markers of mitotic catastrophe were also shown, such as a statistically significant increase in the number of polymorphonuclear cells, giant cells, and micronucleated cells (Figure 3). We also demonstrated such changes in HeLa cells in the case of another anthraquinone, aloe-emodin (12). It should be emphasized that mitotic catastrophe was also observed in cancer cells after the action of chemotherapeutics used in oncology, e.g. bortezomide (13) or etoposide (14). It is also induced by other compounds of plant origin, e.g. vinca alkaloids causing depolymerization of the cytoskeleton, and taxanes that cause hyperpolymerization of microtubules (9). Regardless of the mechanism of action, they lead to the formation of defects in the mitotic apparatus, the consequence of which is the destabilization of microtubule structure, lack of chromosomal segregation, abnormal division, delayed mitosis and giant cell formation, followed by mitotic catastrophe $(9,15)$.

The cell-cycle analysis also showed a significant 9-fold increase in cell proportion in the $\mathrm{G}_{2} / \mathrm{M}$ phase after 48 hours of emodin activity at $100 \mu \mathrm{M}$ relative to the control (Figure 2 ), accompanied by a reduction in the percentage of cells in the $G_{1}$ phase, which is additional confirmation of the induction of mitotic death by emodin. Mitotic catastrophe is characterized by the lack or delay of cell entry into the control point of the $G_{1} / S$ phase, or cell arrest in the $G_{2}$ phase. The majority of tumor cells have an inactive control point at the $\mathrm{G}_{1} / \mathrm{S}$ phase border, which prevents the $\mathrm{G}_{1}$ cycle from being stopped after the action of DNA-damaging factors and leads to the transient accumulation of cells in the $G_{2}$ phase. Because cancer cells also frequently have a inactive $G_{2} / M$ step, they become incapable of stopping the cycle in the $G_{2}$ phase, leading to the entry of cells into the pathway of mitosis and, consequently, mitotic death $(8-11,16,17)$. Mitotic catastrophe is caused by different classes of cytotoxic factors, however, 

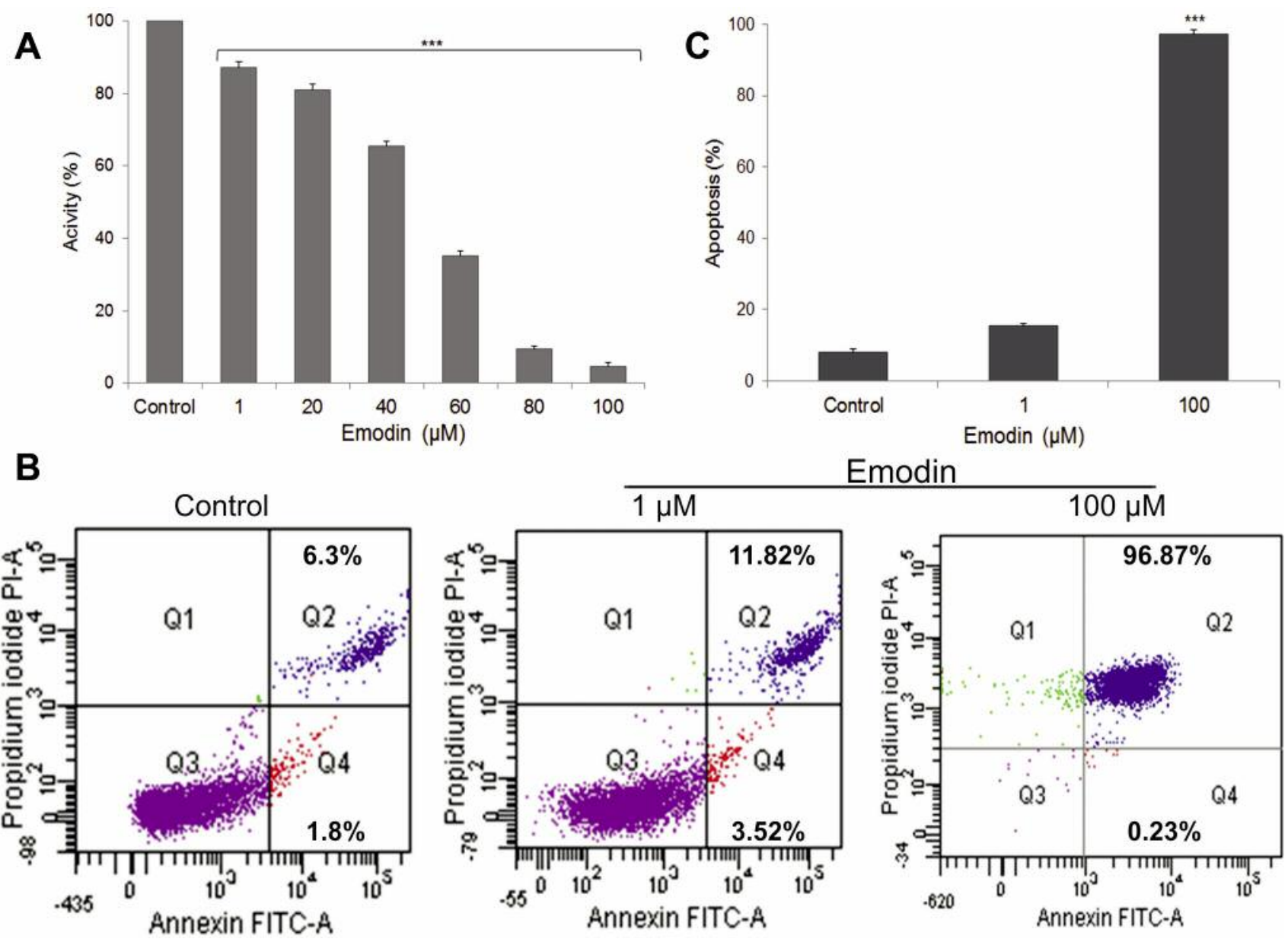

Emodin

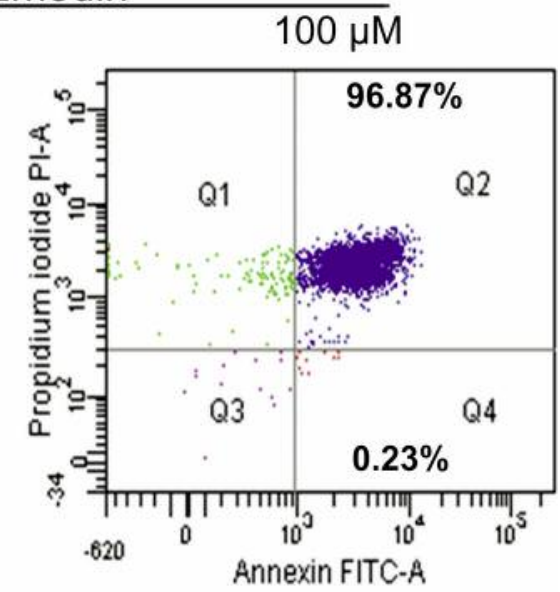

Figure 5. Emodin-induced HeLa cell death. A: Cell viability, as measured by MTT assay after exposure to different concentrations of emodin $(1-100 \mu \mathrm{M})$. ***Differences confirmed statistically at $p<0.001$. B: Apoptosis as evaluated by annexin V-fluorescein isothiocyanate (FITC)/propidium iodide (PI) staining. Cells were treated for $48 \mathrm{~h}$ with $1 \mu \mathrm{M}$ and $100 \mu \mathrm{M}$ emodin. Control cells (not in apoptosis) were without staining with annexin $V$-FITC and PI. The action of emodin resulted in the demonstration of three cell populations: living cells (Q3), cells in the early (Q4) and late stage of apoptosis (Q2), and dead cells (Q1). The data are representative of three parallel experiments. C: Quantification of early and late apoptotic cells induced by emodin.

pathways leading to abnormal mitosis differ depending on the nature of the inducer and the status of cell-cycle checkpoints (18-20). Mitotic death in a further stage leads to fragmentation of the cell nucleus (21), which was also apparent in the cells in this study in the form of increased apoptosis. Emodin has been shown to displace negatively charged phosphatidylserine into the outer monolayer of the cell membrane. This effect was clearly visible in cytometric analysis after 48-h incubation of cells with $100 \mu \mathrm{M}$ emodin, where a highly statistically significant number of apoptotic cells $(96.87 \%$ of cells with late apoptotic phenotype) (Figure 5) correlated with mass arrest of cells in the $\mathrm{G}_{2} / \mathrm{M}$ phase $(63.95 \%$ ) (Figure 2).

Damage to the mitotic apparatus was also demonstrated by labeling the elements of the cytoskeleton, namely F-actin. Emodin affected cytoskeleton reorganization, which was shown by the degradation of labeled actin filaments and the formation into aggregates in the cytoplasm of cells (Figure $6)$. The observed change in the examined cancer cells is very important because F-actin is a component of the cytoskeleton responsible for important functions such as maintaining cell polarity, intracellular structural organization, intracellular transport, growth and cell division, including the formation of mitotic spindles $(22,23)$. Currently, the involvement of the actin cytoskeleton in the process of apoptosis is also being discussed. Cytoskeletal reorganization may affect the initiation and implementation of apoptosis (24-27). The cytoskeleton and compounds affecting it, including those of plant origin, are an important in anti-cancer therapy $(23,24)$.

Our research shows that emodin, depending on the concentration used and incubation time, inhibits mitotic 

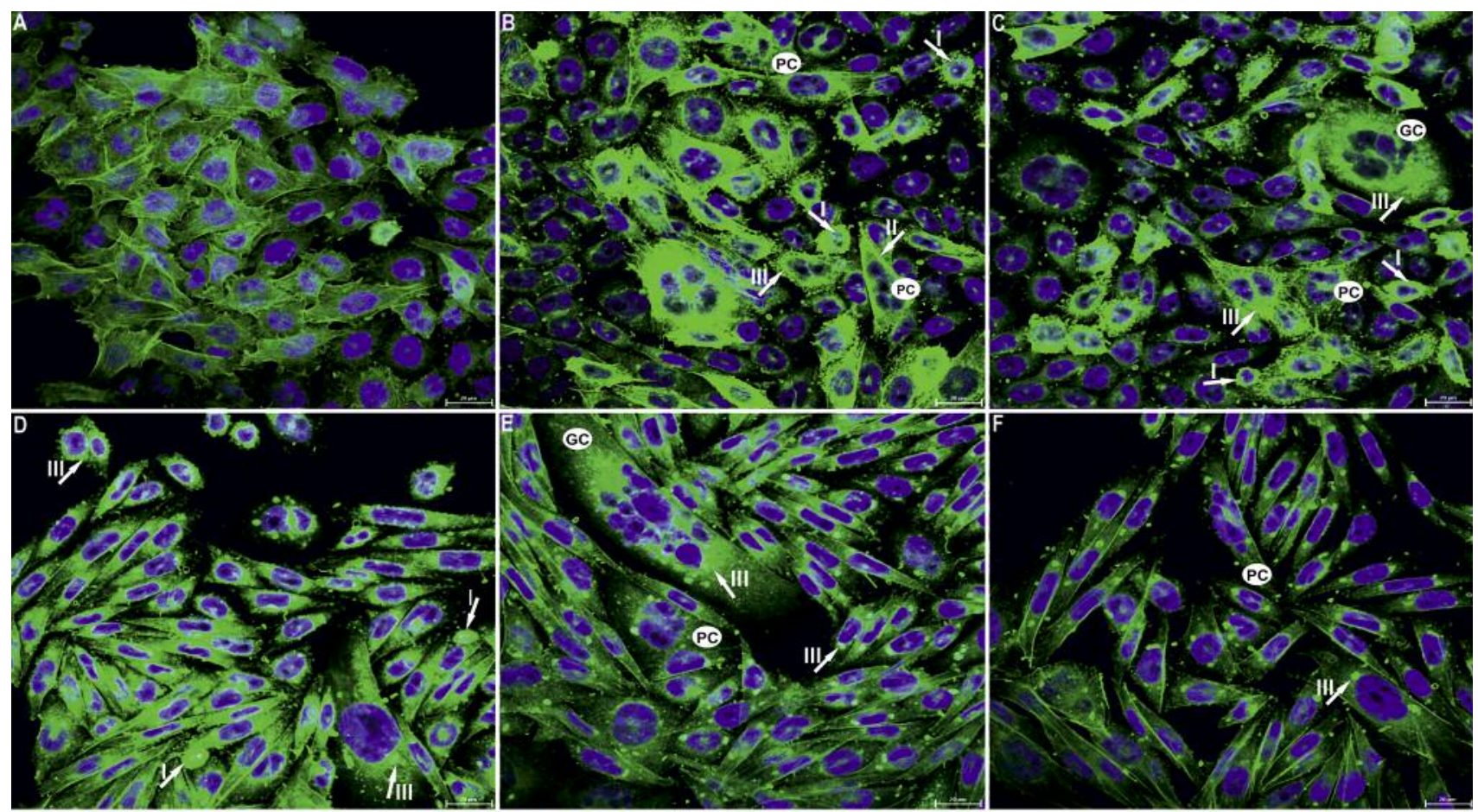

Figure 6. Visualization of the cytoskeleton in HeLa cells using F-actin labeling with phalloidin-fluorescein isothiocyanate, with 4',6-diamidyno-2fenyloindol for cell nuclei. A: Control cells with correctly distributed actin fibers and normal shaped nucleus. B: Cells treated with emodin at $30 \mu \mathrm{M}$, with pronounced intensification of fluorescence of actin filaments often decomposed marginally (arrow II). C: Cells treated with $45 \mu \mathrm{M}$ emodin, with cytoskeleton reorganization and small actin deposits present in the cytoplasm (arrow III). Rounded cells can be seen with condensed actin (arrow I). D: Clear actin deposition (arrow III) and single actin filaments present in the cytoplasm of cells subjected to $100 \mu \mathrm{M}$ emodin treatment, indicating cytoskeletal damage. PC: Polymorphonuclear cells, GC: giant cells. Magnification x400.

activity and induces changes in the cytoskeleton, which induces mitotic death of cervical cancer cells - an alternative type of cancer cell death.

\section{Conflicts of Interest}

All Authors have read the Journal's policy on disclosure of potential conflicts of interest and have none to declare.

\section{Acknowledgements}

This work was supported by Jan Kochanowski University, Grant: 066/R/11.

\section{References}

1 Xie MJ, Ma YH, Miao L, Wang Y, Wang HZ, Xing YY, Xi T and Lu YY: Emodin-provoked oxidative stress induces apoptosis in human colon cancer HCT116 cells through a p53-mitochondrial apoptotic pathway. Asian Pac J Cancer Prev 15: 5201-5205, 2014.

2 Wang Y, Luo Q, He X, Wei H, Wang T, Shao J and Jiang X: Emodin Induces apoptosis of colon cancer cells via induction of autophagy in a ROS-dependent manner. Oncol Res 26: 889-899, 2018 .
3 Chihara T, Shimpo K, Beppu H, Yamamoto N, Kaneko T, Wakamatsu $\mathrm{K}$ and Sonoda S: Effects of aloe-emodin and emodin on proliferation of the MKN45 human gastric cancer cell line. Asian Pac J Cancer Prev 16: 3887-3891, 2015.

4 Sui JQ, Xie KP, Zou W and Xie MJ: Emodin inhibits breast cancer cell proliferation through the ER $\alpha$-MAPK/AKT-cyclin D1/BCL-2 signaling pathway. Asian Pac J Cancer Prev 15: 6247-6251, 2014.

5 Trybus W, Król T, Trybus E, Kopacz-Bednarska A, Król G and Karpowicz E: Changes in the lysosomal system of cervical cancer cells induced by emodin action. Anticancer Res 37: 60876096, 2017.

6 Mossmann T: Rapid colorimetric assay for cellular growth and survival: Application to proliferation and cytotoxicity assays. J Immunol Meth 65: 55-63, 1983.

7 Okada H and Mak TW: Pathways of apoptotic and non-apoptotic death in tumour cells. Nat Rev Cancer 4: 592-603, 2004.

8 Vitale I, Galluzzi L, Castedo M and Kroemer G: Mitotic catastrophe: A mechanism for avoiding genomic instability. Nat Rev Mol Cell Biol 12: 385-92, 2011.

9 Vakifahmetoglu H, Olsson M and Zhivotovsky B: Death through a tragedy: Mitotic catastrophe. Cell Death Differ 15: 1153-1162, 2008.

10 Castedo M, Perfettini JL, Roumier T, Valent A, Raslova H, Yakushijin K, Horne D, Feunteun J, Lenoir G, Medema R, 
Vainchenker W and Kroemer G: Mitotic catastrophe constitutes a special case of apoptosis whose suppression entails aneuploidy. J Oncogene 23: 4362-4370, 2004.

11 Portugal J, Mansilla S and Bataller M: Mechanisms of druginduced mitotic catastrophe in cancer. Curr Pharm Des 16: 6978, 2010.

12 Trybus W, Król T, Trybus E, Stachurska A, Kopacz-Bednarska $A$ and Król G: Induction of mitotic catastrophe in human cervical cancer cells after administration of aloe-emodin. Anticancer Res 38: 2037-2044, 2018.

13 Gu JJ, Kaufman GP, Mavis C, Czuczman MS and HernandezIlizaliturri FJ: Mitotic catastrophe and cell-cycle arrest are alternative cell death pathways executed by bortezomib in rituximab resistant B-cell lymphoma cells. Oncotarget 8: 1274112753, 2017.

14 Rello-Varona S, Gámez A, Moreno V, Stockert JC, Cristóbal J, Pacheco M, Cañete M, Juarranz A and Villanueva A: Metaphase arrest and cell death induced by etoposide on HeLa cells. Int $\mathbf{J}$ Biochem Cell Biol 38: 2183-95, 2006.

15 Radford IR and Murphy TK: Radiation response of mouse lymphoid and myeloid cell lines. Part III. Different signals can lead to apoptosis and may influence sensitivity to killing by DNA double-strand breakage. Int J Radiat Biol 65: 229-239, 1994.

16 Erenpreisa $\mathrm{J}$ and Cragg MS: Mitotic death: A mechanism of survival? A review. Cancer Cell Int 1: 1-7, 2001.

17 Horbay R and Stoika R: Giant cell formation: The way to cell death or cell survival? Cent Eur J Biol 6: 675-684, 2011.

18 Mansilla S, Bataller M and Portugal J: Mitotic catastrophe as a consequence of chemotherapy, Anticancer Agents Med Chem 6: 589-602, 2006.
19 Roninson IB, Broude EV and Chang BD: If not apoptosis, then what? Treatment-induced senescence and mitotic catastrophe in tumor cells. Drug Resist Updat 4: 303-13, 2001.

20 Singh R, George J and Shukla Y: Role of senescence and mitotic catastrophe in cancer therapy. Cell Div 5: 1-12, 2010.

21 Barbisan LF, Mello ML, Russo J and Vidal BC: Apoptosis and catastrophic cell death in benzo[a]pyrene-transformed human breast epithelial cells. Mutat Res 431: 133-9, 1999.

22 Jordan MA and Wilson L: Microtubules as a target for anticancer drugs. Nat Rev Cancer 4: 253-265, 2004.

23 Mukhtar E, Adhami VM and Mukhtar H: Targeting microtubules by natural agents for cancer therapy. Mol Cancer Ther 13: 275284, 2014.

24 Franklin-Tong VE and Gourlay CW: A role for actin in regulating apoptosis/programmed cell death: evidence spanning yeast, plants and animals. Biochem J 413: 389-404, 2008.

25 Grzanka D, Gagat $M$ and Izdebska $M$ : Actin is required for cellular death. Acta Histochem 115: 775-82, 2013.

26 Desouza M, Gunning PW and Stehn JR: The actin cytoskeleton as a sensor and mediator of apoptosis. Bioarchitecture 2: 75-87, 2012.

27 Gourlay CW and Ayscough KR: The actin cytoskeleton in ageing and apoptosis. FEMS Yeast Res 5: 1193-1198, 2005.

Received December 4, 2018

Revised December 13, 2018

Accepted December 14, 2018 